OPEN ACCESS

Edited by:

Po-Hsiang Tsui,

Chang Gung University, Taiwan

Reviewed by:

Xiaoming Yang

University of Washington,

United States

Ji Hoon Shin,

University of Ulsan, South Korea

*Correspondence:

Zhongmin Wang

wzm0722@hotmail.com

tThese authors have contributed

equally to this work

Specialty section:

This article was submitted to Cancer Imaging and Image-directed

Interventions,

a section of the journa

Frontiers in Oncology

Received: 25 December 2019

Accepted: 30 July 2020

Published: 25 August 2020

Citation:

Huang $W, L U J$, Tang $R, W u Z$, Wang Q, Ding X, Wang Z and Chen K (2020) Phase Contrast Imaging Based

Microbubble Monitoring

of Radiofrequency Ablation: An

ex vivo Study. Front. Oncol. 10:1709.

doi: 10.3389/fonc.2020.01709

\section{Phase Contrast Imaging Based Microbubble Monitoring of Radiofrequency Ablation: An ex vivo Study}

\author{
Wei Huang ${ }^{1+}$, Jian Lu' ${ }^{2 t}$, Rongbiao Tang ${ }^{1}$, Zhiyuan Wu ${ }^{1}$, Qingbing Wang ${ }^{1}$, Xiaoyi Ding ${ }^{1}$, \\ Zhongmin Wang ${ }^{2 *}$ and Kemin Chen ${ }^{1}$
}

${ }^{1}$ Department of Radiology, Ruijin Hospital, School of Medicine, Shanghai Jiaotong University, Shanghai, China, ${ }^{2}$ Department of Radiology, Ruijin Hospital/Luwan Branch, School of Medicine, Shanghai Jiaotong University, Shanghai, China

Background: To explore the potential of synchrotron radiation (SR) phase contrast imaging $(\mathrm{PCl})$ for real-time microbubble formation monitoring during radiofrequency ablation (RFA).

Methods: RFA was performed on ex vivo porcine muscle tissue using unipolar and multi-tined expandable electrodes. Images of microbubble formation in the samples were captured by both SR PCl and absorption contrast imaging. The synchronous ablation temperature was recorded. Each RFA electrode type group contained 6 samples. Ablation size was assessed by histologic examination.

Results: Microbubble formation during RFA could be visualized by SR PCl. The diameter of the microbubbles revealed on the image ranged from tens of microns to several millimeters, and these microbubbles first appeared at the edge of the RFA electrode when the target region temperature reached approximately $60^{\circ} \mathrm{C}$ and rapidly extended outwards. The average microbubble range measured on $\mathrm{PCl}$ was $17.66 \pm 0.74 \mathrm{~mm}$. The average range of coagulation necrosis measured by histological examination was $17.22 \pm 0.38 \mathrm{~mm}$. There was no significant difference between them $(P>0.05)$. The range of microbubbles corresponded to the ablation zone.

Conclusion: $\mathrm{PCl}$ enabled real-time high-resolution visualization of microbubble formation during RFA, indicating a potential for its use in ablation monitoring.

Keywords: radiofrequency ablation, synchrotron, microbubbles, radiation, phase contrast imaging

\section{BACKGROUND}

Radiofrequency ablation (RFA) has gained widespread acceptance in the local therapy of various benign and malignant solid lesions, particularly those involving the liver, lung, kidney and musculoskeletal system (1-8). It is usually performed percutaneously under image guidance and is appropriate for inoperable patients with comorbidities.

Abbreviations: ACI, absorption contrast imaging; CT, computed tomography; MRI, magnetic resonance imaging; PCI, phase contrast imaging; RFA, radiofrequency ablation; SR, synchrotron radiation; US, ultrasound. 
In clinical practice, it is difficult to predict the RFA zone. The size and shape of the RFA zone can vary according to many factors, including the location of the lesion, the histological characteristics of the lesion and adjacent tissues, the type of electrode, duration of ablation and the heat sink phenomenon (9-11). This disadvantage may explain why the local recurrence rate after RFA is higher than that after surgery, especially for voluminous lesions (12-16). Some studies show a sharp rise in the rate of local recurrences and a decline of overall survival for tumors over $3-5 \mathrm{~cm}$ (17-19). And nowadays, the indication of RFA is usually limited to the lesions less than $5 \mathrm{~cm}$. If the RFA zone can be monitored accurately during the procedure, the relatively high local residue and recurrence rate could be overcome.

Currently, RFA procedures are generally performed under ultrasound (US), computed tomography (CT), or magnetic resonance imaging (MRI) guidance (20-27). These traditional image guidance methods can help to localize the RFA electrode to the lesion site but do not serve as a real-time monitoring tool to evaluate the ablation zone during the procedure due to their physical limitations. To overcome these disadvantages, a new monitoring method should be employed. Synchrotron radiation (SR) phase contrast imaging (PCI) is more functional than conditional absorption contrast imaging (ACI) and is characterized by its high spatial resolution of sub-micron level and high temporal resolution of milliseconds (28-30). Moreover, according to the phase shift caused by variations in the refractive index and thickness of materials (31), PCI is effective at the border of two different structures and can provide significant edge enhancement for low-density materials, including gas, organic materials, and soft tissues (29, 32-34).

In previous studies, the range of microbubbles formed during RFA corresponded to the RFA zone $(35,36)$. Therefore, in this study, we planned to use PCI to reveal microbubble formation during RFA using two different types of frequently used RFA electrodes and evaluate the potential for real-time monitoring of RFA.

\section{MATERIALS AND METHODS}

All experiments were conducted in accordance with the guidelines established and approved by Shanghai Jiao Tong University's Institutional Animal Care and Use Committee (Approval number: B-2015-011).

\section{Sample Preparation}

Porcine muscle (Lingchang Biotech, Shanghai, China) was used and cut into appropriately sized samples $(3 \times 3 \times 3 \mathrm{~cm}$ for the multi-tined electrode, $2.5 \times 2.5 \times 2.5 \mathrm{~cm}$ for the unipolar electrode).

In clinical practice, RFA is most frequently applied to liver and muscular like tissue. Porcine liver was excluded at this study, because ex vivo hepatic vessels contain gas, which can be revealed by PCI and hamper the observation of micro-bubble formation during RFA.

\section{SR Parameters}

The study was performed in the BL13W1 beamline at the Shanghai Synchrotron Radiation Facility (SSRF, China). A $3.5 \mathrm{GeV}$ electron storage ring generated $\mathrm{X}$-rays with an energy range of $8-72.5 \mathrm{keV}$ and an average beam current of $180 \mathrm{~mA}$. X-rays were then monochromatized by a doublecrystal monochromator with Si (111) and Si (311) crystals at an energy level of $22 \mathrm{KeV}$. Energy resolution was $\Delta \mathrm{E} / \mathrm{E}<5 \times 10^{3}$. Incoming $\mathrm{X}$-rays were converted into visible light using a $100 \mu \mathrm{m}$ thick CdWO4 cleaved single crystal scintillator and consecutively captured by a CCD camera (Photonic Science, Britain) with pixel size of $9 \mu \mathrm{m}$. The sample was placed $34 \mathrm{~m}$ downstream of the SR source. The distance between the sample and the CCD camera had a changeable range of $8 \mathrm{~m}$.

\section{$\mathrm{ACl}$ and $\mathrm{PCl}$ Parameters}

A total of $0.2 \mathrm{ml}$ of gas was injected into the central of one $2.5 \times 2.5 \times 2.5 \mathrm{~cm}$ sample by a $17 \mathrm{G}$ needle, in order to identify the different presentation of bubbles on SR ACI and PCI.

Synchrotron radiation images of this sample were obtained at $22 \mathrm{KeV}$ with two different object-to-detector distances of 10 and $600 \mathrm{~mm}$. At an object-to-detector distance of $10 \mathrm{~mm}$, detector was placed immediately behind the sample, the phase contrast effect is minimal, ACI was obtained (Figure 1A). The phase contrast effect increases with the augmentation of object-todetector distance. At an object-to-detector distance of $600 \mathrm{~mm}$, PCI can be captured (Figure 1B). As the quality of visible bubbles using PCI was greater than that using ACI. PCI was then used to monitor the following RFA procedure.

\section{RFA Parameters}

Radiofrequency ablation was performed with a RITA Model 1500X radiofrequency generator, $250 \mathrm{~W}, 460 \mathrm{~Hz}$ frequency (RITA Medical Systems, Mountain View, CA, United States). The RFA electrodes included a unipolar electrode and multi-tined expandable electrodes. The RFA time was $7 \mathrm{~min}$ for the unipolar electrode and $5 \mathrm{~min}$ for the multi-tined expandable electrodes with a $1 \mathrm{~cm}$ expandable range. The energy level was $90 \mathrm{~W}$. The target goal temperature was set to $105^{\circ} \mathrm{C}$, and the real-time actual temperature was measured by thermodetectors in the electrodes. The RFA electrodes were localized to the center of the sample, which was placed on a translation stage. The electrode axis was perpendicular to the synchrotron source and confirmed by SR fluoroscopy. The loop electrode was adhered to the underside of the sample. Each RFA electrode type group contained six samples, and there were 12 RFA ablations performed during the course of this study.

\section{Image Acquisition}

Images were captured with an exposure time of $40 \mathrm{~ms}$ at 98 frames per minute. Background noise was eliminated using Image-Pro Plus 6.0 (Media Cybernetics Inc., United States), and image quality was compared. The microbubble formation process was pseudo-colored using a normalization algorithm via MATLAB 7.0 (MathWorks, United States). The range 


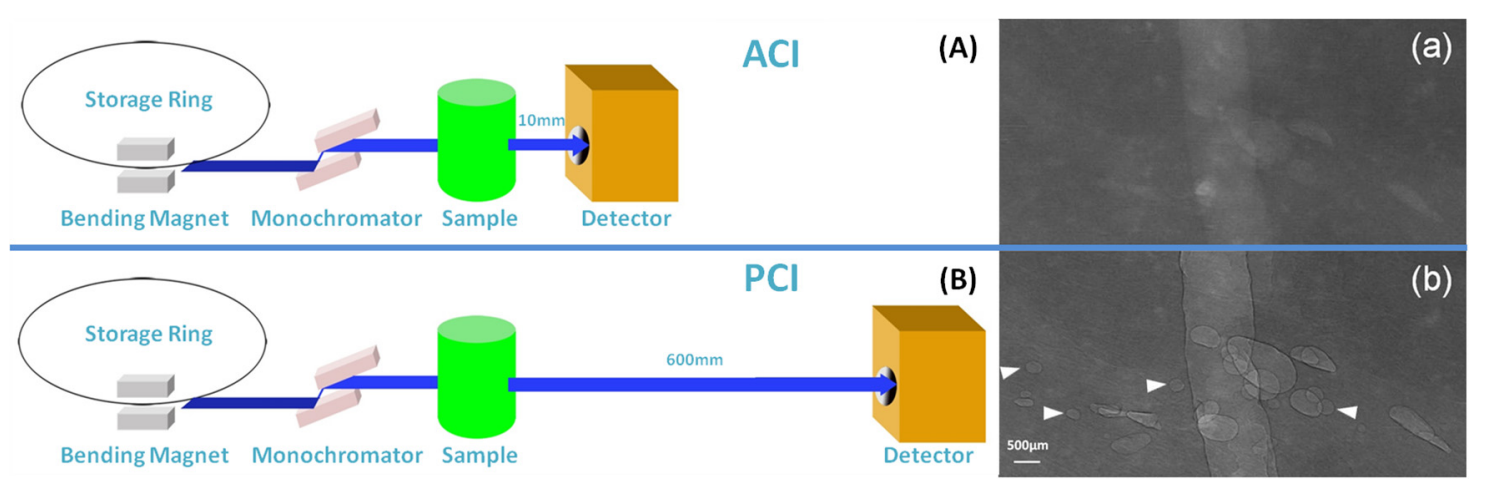

FIGURE 1 | Schematic of SR ACl and PCl, and the images of the bubbles. SR images of the same sample were obtained at $22 \mathrm{KeV}$ with two different object-to-detector distances of 10 and $600 \mathrm{~mm}$. At a distance of $10 \mathrm{~mm}, \mathrm{ACl}$ was obtained (A); at a distance of $600 \mathrm{~mm}, \mathrm{PCl}$ was captured (B). Bubbles could be clearly depicted by $\mathrm{PCl}$ and displayed good contrast with the peripheral tissue, especially the sharp edges (b). The contrast between bubbles and surrounding tissues was not clear in $\mathrm{ACl}$ (a). Arrows indicate bubbles visible by PCl but invisible by $\mathrm{ACl}$. The pixel size was $9 \mu \mathrm{m} \times 9 \mu \mathrm{m}$, and the exposure time was $40 \mathrm{~ms}$.

of microbubbles, RFA temperature and RFA time were synchronously recorded.

\section{Pathological Analysis}

Samples were bisected across the long axe of the electrode track for immediate gross examination. The width of the RFA ablation zone was measured by calipers. The sample was then fixed in $10 \%$ formalin and later stained with hematoxylin and eosin (H\&E) for histomorphological analysis.

\section{Statistical Analysis}

The data are presented as the means \pm standard error. Using SPSS 19.0 software, the range of microbubble measured on the PCI and the range of RFA zone showed on gross examination and histomorphological analysis were compared using the paired $t$-test. A $P$-value of less than 0.05 was defined as statistically significant.

\section{RESULTS}

\section{Comparison of Bubble Morphology Between $\mathrm{PCl}$ and $\mathrm{ACl}$}

The PCI and ACI characteristics of bubbles are displayed in Figure 1 after an injection of gas in the same sample. The contrast between bubbles and surrounding tissue was not clear in ACI (Figure 1a). After adjusting the sample-to-detector distance to $600 \mathrm{~mm}$, bubbles with sharp edges could be clearly visualized by PCI (Figure 1b). The quality of visible bubbles using PCI was greater than that using ACI.

\section{$\mathrm{PCl}$ of Microbubble Formation During RFA}

Images were obtained $20 \mathrm{~s}$ after RFA began. For the unipolar electrode, $40 \mathrm{~s}$ after RFA began, when the local temperature reached approximately $60^{\circ} \mathrm{C}$, microbubbles began to appear at the electrode edge. For the multi-tined expandable electrodes, $60 \mathrm{~s}$ after RFA began, microbubbles began to appear at the same temperature of $60^{\circ} \mathrm{C}$. During RFA, from the electrode surface outward, the newly generated microbubbles were irregular and cleft-like in shape. As the temperature rose, microbubbles continued to increase and expand rapidly outward. The density and range of microbubbles increased with the rise in temperature and RFA duration. The complete microbubble diffusion process was revealed and pseudo-colored (Figures 2, 3).

The RFA temperature-time curve and microbubble rangetime curve of the unipolar electrode were recorded (Figure 4).

\section{$\mathrm{PCl}$ of Microbubble Transformation After RFA}

Images were captured from 10 to $30 \mathrm{~min}$ after RFA. Microbubbles remained in the tissue. Gradually, the microbubbles became regular circle- or oval-shaped and displayed a tendency to fuse together. The diameter of the microbubbles ranged from tens of microns to several millimeters (Figure 5).

\section{Tissue Section Images After RFA}

Sectional images of the sample and pathological sections (Figure 6) were obtained after RFA.

Radiofrequency ablation was performed on six samples using a unipolar electrode. The average microbubble range measured on PCI was $17.66 \pm 0.74 \mathrm{~mm}$. The average range of coagulation necrosis (including complete and partial coagulation necrotic areas) measured by histological examination was $17.22 \pm 0.38 \mathrm{~mm}$. There was no significant difference between them $(P>0.05)$.

The diameter of the ablation zone of the multi-tined expandable electrodes was more than $20 \mathrm{~mm}$. The final microbubble range could not be measured because the field of our CCD vision was limited to $20 \mathrm{~mm}$.

\section{DISCUSSION}

Radiofrequency ablation electrodes can deliver a high-frequency sinusoidal electromagnetic current that induces agitation of tissue 

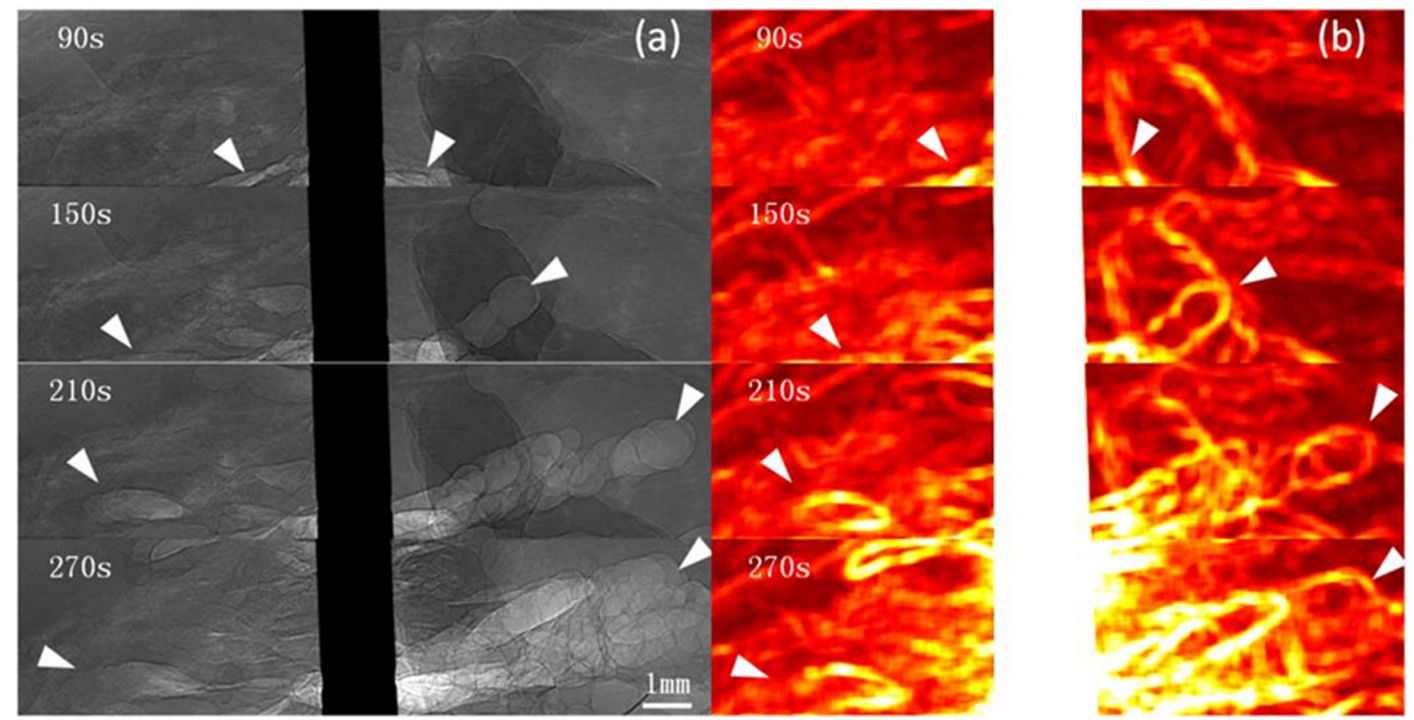

FIGURE 2 | PCI of microbubble diffusion process during unipolar electrode RFA. PCl of the microbubble diffusion process during RFA using a unipolar electrode (a) and pseudo-colored with a normalization algorithm (b).Microbubbles were revealed $40 \mathrm{~s}$ after ablation and distributed at the edge of the electrode and adjacent tissues. From the electrode surface outward, microbubbles continued to increase and expand rapidly. The density and range of microbubbles increased with the rise in temperature and RFA duration (a). The range of microbubbles is highlighted on the pseudo-colored image (b). Arrowheads indicate microbubble ranges. The pixel size was $9 \mu \mathrm{m} \times 9 \mu \mathrm{m}$, and the exposure time was $40 \mathrm{~ms}$.

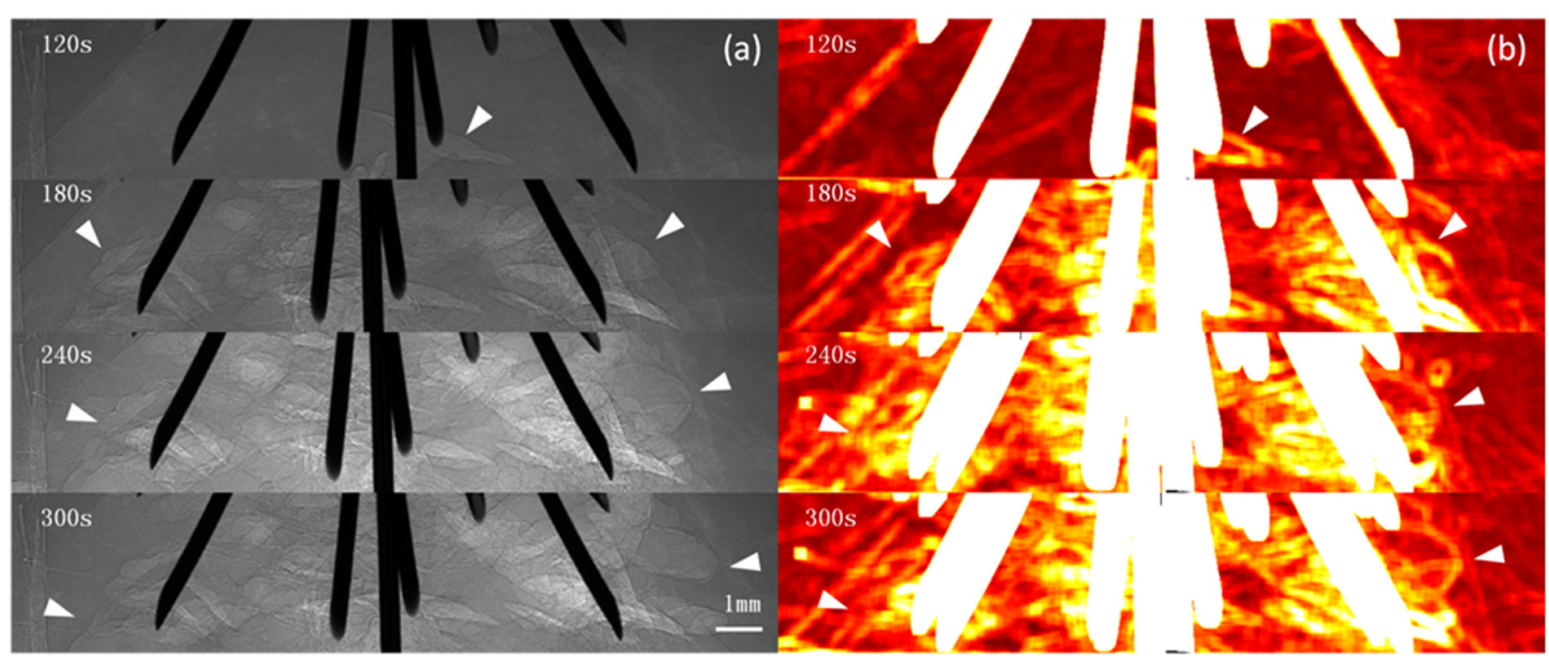

FIGURE 3 | PCI of microbubble diffusion process during multi-tined expandable electrodes RFA. PCl of the microbubble diffusion process during RFA using multi-tined expandable electrodes (a) and pseudo-colored with a normalization algorithm (b).Microbubbles first appeared at the edge of electrodes $60 \mathrm{~s}$ after ablation when the temperature reached $60^{\circ} \mathrm{C}$ (a). Cleft-like microbubbles; microbubbles continued to increase and expand rapidly outward. The distribution of microbubbles could be monitored in real time by $\mathrm{PCl}$ (a). The highlighted area corresponding to the microbubble range first appeared at the edge of the electrodes and then spread into surrounding tissues (b). Arrowheads indicate microbubble ranges. The pixel size was $9 \mu \mathrm{m} \times 9 \mu \mathrm{m}$, and the exposure time was $40 \mathrm{~ms}$.

ions, after which energy dissipates as heat through ionic friction (37). If the tissue temperature reaches approximately $60^{\circ} \mathrm{C}$ and this temperature is maintained for a few seconds, irreversible damage can occur due to DNA denaturation, manifesting as coagulation necrosis (9).

The key point of real-time monitoring of RFA is to identify coagulation necrosis from the adjacent tissue. However, the problem in exact quantification of the coagulation necrotic zone still prevails and hinders the treatment effect of RFA therapy (38). The imaging techniques used during the RFA procedure include US, CT, and MRI, which serve as ideal guidance tools. However, they have some limitations in the real-time monitoring of the ablation area. Hypersonic microbubble formation during the ablation and acoustic shadow of the RFA electrode shield the 

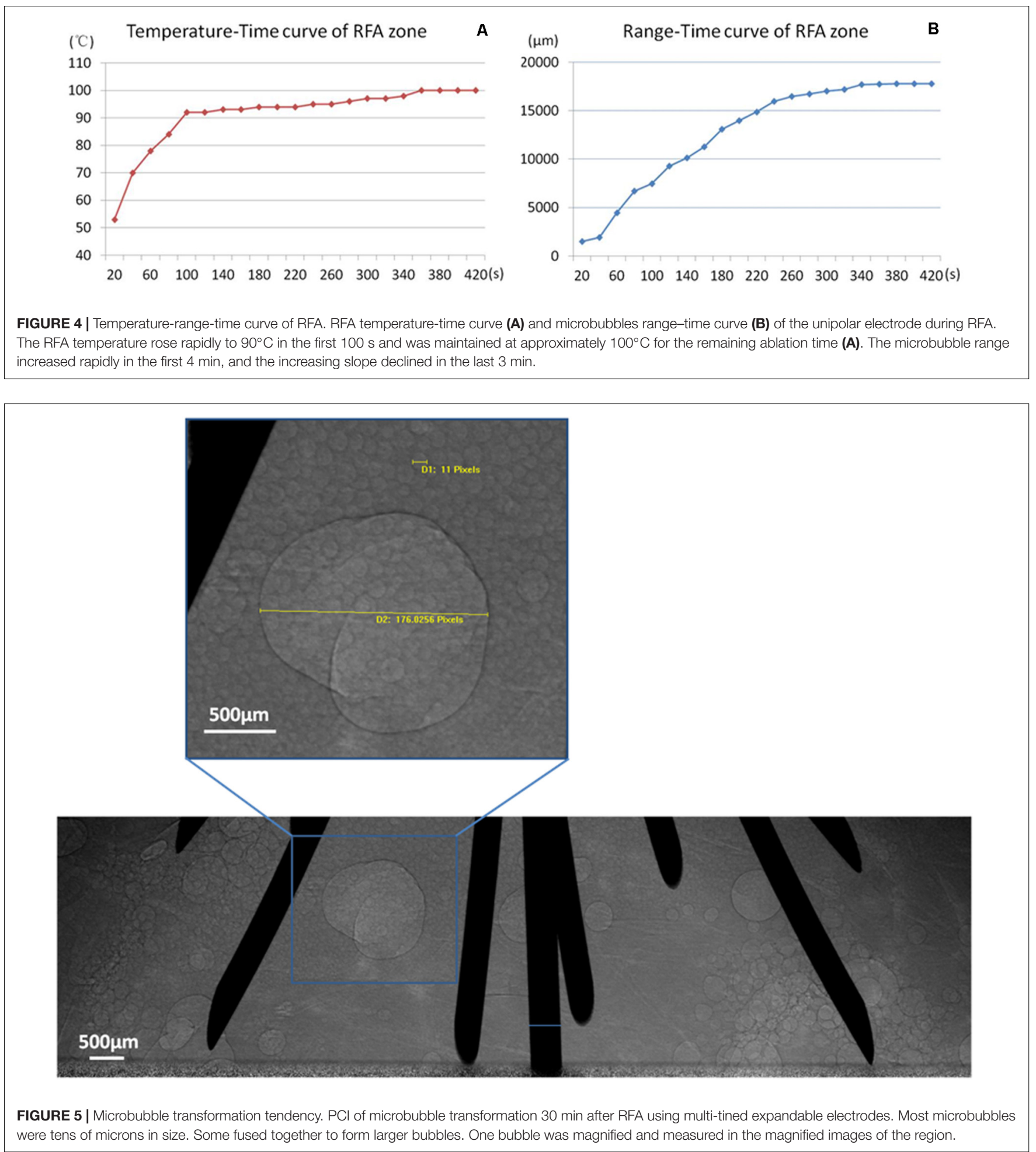

lesion and impair the quality of US images $(35,39)$. CT cannot clearly delineate the boundary between the coagulation zone and the area of peripheral edema because of their similar densities. Frequency interference between the RF generator and the MR imager is difficult to avoid. Most current MRI and RFA devices do not allow for simultaneous MRI and the application of RFA energy (25).

Previous studies have used US and US Nakagami imaging to monitor RFA microbubble formation, the range of which corresponded with the ablation zone $(35,36)$. However, 


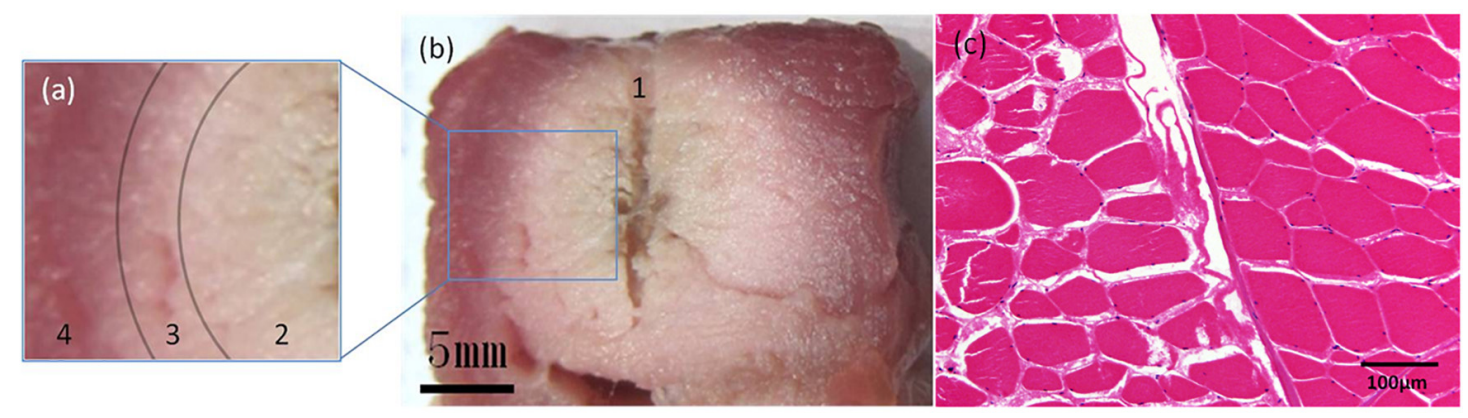

FIGURE 6 | Pathological examinations. Sectional images and H\&E-stained image of the sample after RFA using a unipolar electrode. On sectional images (a,b), the sample could be divided into 4 parts: 1 . The central fissure is the trace of the unipolar electrode; 2 . the adjacent white region indicates complete coagulation necrosis; 3. the pink transitional region indicates partial coagulation necrosis; and 4. the peripheral red region depicts intact tissue. The transition between parts 2 , 3 , and 4 is gradual. On the H\&E-stained image (c), the ablation zone is on the left half. Muscle bundles fissure after RFA, and their interval is enlarged. Cytoplasm of muscle cells appears pink, and the nuclei are dark and faint.

microbubbles of tens of microns in diameter cannot be directly visualized using US imaging, as it has limited spatial resolution. Moreover, the posterior margin of the ablation zone is difficult to observe due to electrode acoustic shadow and irregular reflections of ultrasound by microbubbles (35).

Variations in the refractive index between gas and soft tissue are evident and can cause an edge enhancement effect on PCI. This effect is a significant advantage of PCI and is the result of the high spatial coherence of inline PCI achievable with a large object-to-detector distance (32). PCI is more suitable for microbubble observation than $\mathrm{ACI}$ and can reveal microbubbles of tens of microns in size. With the characteristic of high temporal resolution, PCI can even detect microbubbles newly formed on the surface of RFA electrodes. In our study, microbubble formation during the entire RFA procedure and the transformation after RFA could be directly visualized by PCI.

The hypothesis of microbubble formation during RFA is as follows. First, when the temperature of the tissue reaches the boiling point, vapor is generated in the form of microbubbles. Second, microbubbles in the blood within microvessels flow out because of the hyperemia induced by ablation (40). As the samples used in this study were ex vivo, the potential interference of microvessels could be excluded, and the first hypothesis might be more reasonable.

Microbubbles appeared when the temperature increased and diffused outward from the surface of RFA electrodes. We observed a phenomenon during this procedure: the temperature threshold of microbubble formation was $60^{\circ} \mathrm{C}$, which is much lower than the boiling point of water. There are two possible explanations: First, because of the relatively low heat conductivity of the tissue, vapor could be generated at $60^{\circ} \mathrm{C}$ and manifest as microbubbles. Second, local temperature may have reached the boiling point, but the area may be limited and could not be accurately measured by thermodetectors in the electrodes. The relationship between microbubble formation and the exact local temperature should be explored in future studies.

Nevertheless, microbubble formation indicates that the local tissue temperature has reached at least $60^{\circ} \mathrm{C}$. At this temperature, coagulation necrosis in tissues is irreversible (9). According to this phenomenon, the microbubble range revealed by PCI may reflect the coagulation necrotic area.

After RFA, microbubbles remained in the ablation zone on PCI. Some fused together and formed bubbles of several millimeters in diameter. This phenomenon can explain the origin of bubbles observed on CT images in some clinical cases after RFA (9).

In previous studies, SR PCI has showed some advantages in the clinical imaging diagnostic domain. Compared to the traditional mammography, the image quality was improved by using PCI $(41,42)$. A significant reduction of radiation dose was obtained by SR high resolution CT (43). According to our study, with its high resolution of low-density materials and high temporal resolution, SR PCI has the potential to be used in real-time monitoring of the RFA zone via microbubble imaging.

There are some limitations to our study. First, an ex vivo study might not reflect actual microbubble transformation in vivo, and the influence of microvessel perfusion and the heat sink phenomenon should be considered. Second, the RFA zone of multi-tined expandable electrodes was larger than the field of the CCD, and its range could not be measured by PCI. Third, although in our study, the range of microbubbles after RFA using unipolar electrodes was close to that measured on histological cross-sections, which contained complete and partial coagulation necrotic areas; additionally, the transition between complete coagulation necrosis and partial coagulation necrosis was gradual, and the boundary was indistinct. Further quantitative studies should be carried out to analyze the relationship between the density of microbubbles and the degree of coagulation necrosis.

\section{CONCLUSION}

Synchrotron radiation PCI enabled real-time high-resolution visualization of microbubble formation during RFA. The temperature threshold of micro-bubble appearance was about $60^{\circ} \mathrm{C}$. At this temperature level, protein denaturation and cellular 
damage is irreversible, meaning that the range of micro-bubbles corresponds with cell necrosis area, which was confirmed by pathological examinations in our study. In summary, SR PCI has a potential for real-time monitoring of RFA zone.

\section{DATA AVAILABILITY STATEMENT}

The datasets generated for this study are available on request to the corresponding author.

\section{ETHICS STATEMENT}

The animal study was reviewed and approved by the Shanghai Jiao Tong University School of Medicine Institutional Animal Care \& Use Committee.

\section{REFERENCES}

1. Kim YS, Lim HK, Rhim H, Lee MW, Choi D, Lee WJ, et al. Ten-year outcomes of percutaneous radiofrequency ablation as first-line therapy of early hepatocellular carcinoma: analysis of prognostic factors. J Hepatol. (2013) 58:89-97. doi: 10.1016/j.jhep.2012.09.020

2. Stoltz A, Gagniere J, Dupre A, Rivoire M. Radiofrequency ablation for colorectal liver metastases. J Visc Surg. (2014) 151(Suppl. 1):S33-44. doi: 10.1016/j.jviscsurg.2013.12.005

3. Lanuti M, Sharma A, Digumarthy SR, Wright CD, Donahue DM, Wain JC, et al. Radiofrequency ablation for treatment of medically inoperable stage I non-small cell lung cancer. J Thorac Cardiovasc Surg. (2009) 137:160-6.

4. Lyons NJ, Pathak S, Daniels IR, Spiers A, Smart NJ. Percutaneous management of pulmonary metastases arising from colorectal cancer; a systematic review. Eur J Surg Oncol. (2015) 41:1447-55.

5. Breen DJ, Rutherford EE, Stedman B, Roy-Choudhury SH, Cast JE, Hayes $\mathrm{MC}$, et al. Management of renal tumors by image-guided radiofrequency ablation: experience in 105 tumors. Cardiovasc Intervent Radiol. (2007) 30:936-42.

6. Gervais DA, McGovern FJ, Arellano RS, McDougal WS, Mueller PR. Radiofrequency ablation of renal cell carcinoma: part 1, Indications, results, and role in patient management over a 6-year period and ablation of 100 tumors. AJR Am J Roentgenol. (2005) 185:64-71. doi: 10.2214/ajr.185.1. 01850064

7. Botsa E, Mylona S, Koutsogiannis I, Koundouraki A, Thanos L. CT image guided thermal ablation techniques for palliation of painful bone metastases. Ann Palliat Med. (2014) 3:47-53.

8. Motamedi D, Learch TJ, Ishimitsu DN, Motamedi K, Katz MD, Brien EW, et al. Thermal ablation of osteoid osteoma: overview and step-by-step guide. Radiographics. (2009) 29:2127-41.

9. Kim YS, Rhim H, Lim HK, Choi D, Lee MW, Park MJ. Coagulation necrosis induced by radiofrequency ablation in the liver: histopathologic and radiologic review of usual to extremely rare changes. Radiographics. (2011) 31:377-90.

10. dos Santos I, Haemmerich D, Pinheiro Cda S, da Rocha AF. Effect of variable heat transfer coefficient on tissue temperature next to a large vessel during radiofrequency tumor ablation. Biomed Eng Online. (2008) 7:21. doi: 10.1186/ 1475-925x-7-21

11. Pillai K, Akhter J, Chua TC, Shehata M, Alzahrani N, Al-Alem I, et al. Heat sink effect on tumor ablation characteristics as observed in monopolar radiofrequency, bipolar radiofrequency, and microwave, using ex vivo calf liver model. Medicine. (2015) 94:e580. doi: 10.1097/md.0000000000000580

12. Ito $\mathrm{T}$, Tanaka $\mathrm{S}$, Iwai $\mathrm{S}$, Takemura $\mathrm{S}$, Hagihara A, Uchida-Kobayashi S, et al. Outcomes of laparoscopic hepatic resection versus percutaneous

\section{AUTHOR CONTRIBUTIONS}

$\mathrm{WH}, \mathrm{JL}$, and ZWa designed the research and supervised the report. $\mathrm{ZWu}$ and $\mathrm{RT}$ performed the research. WH and JL wrote the manuscript. $\mathrm{XD}, \mathrm{KC}$, and $\mathrm{ZWa}$ supervised the report. $\mathrm{KC}$, $\mathrm{ZWu}$, and QW analyzed the data. All authors contributed to the article and approved the submitted version.

\section{FUNDING}

This work was supported by the National Science Foundation of China (Nos. 81471808 and 81771949), Shanghai Municipal Commission of Health and Family Planning (No. 201640087), Clinical Key Specialist Construction Project of Shanghai Municipal Health Commission [Interventional Radiology (No. shslczdzk06002) \& 3D Printing (No. shslczdzk07002)], and Shanghai Municipal Key Clinical Specialty (No. ZK2019A02). The above foundations are all related to the content of the article.

radiofrequency ablation for hepatocellular carcinoma located at the liver surface: a case-controlled study with propensity score matching. Hepatol Res. (2015) 46:565-74. doi: 10.1111/hepr.12592

13. Han K, Ko HK, Kim KW, Won HJ, Shin YM, Kim PN. Radiofrequency ablation in the treatment of unresectable intrahepatic cholangiocarcinoma: systematic review and meta-analysis. J Vasc Interv Radiol. (2015) 26:943-8.

14. Weis S, Franke A, Mossner J, Jakobsen JC, Schoppmeyer K. Radiofrequency (thermal) ablation versus no intervention or other interventions for hepatocellular carcinoma. Cochrane Database Syst Rev. (2013) 12:CD003046. doi: 10.1002/14651858.CD003046.pub3

15. Wang Y, Luo Q, Li Y, Deng S, Wei S, Li X. Radiofrequency ablation versus hepatic resection for small hepatocellular carcinomas: a meta-analysis of randomized and nonrandomized controlled trials. PLoS One. (2014) 9:e84484. doi: 10.1371/journal.pone.0084484

16. Hasegawa K, Kokudo N, Makuuchi M, Izumi N, Ichida T, Kudo M, et al. Comparison of resection and ablation for hepatocellular carcinoma: a cohort study based on a Japanese nationwide survey. J Hepatol. (2013) 58:724-9.

17. Seror O, N'Kontchou G, Ibraheem M, Ajavon Y, Barrucand C, Ganne N, et al. Large ( $>$ or $=5.0-\mathrm{cm}$ ) HCCs: multipolar RF ablation with three internally cooled bipolar electrodes-initial experience in 26 patients. Radiology. (2008) 248:288-96. doi: 10.1148/radiol.2481071101

18. Morgan JH III, Royer GM, Hackett P, Gamblin TC, McCampbell BL, Conforti A, et al. Radio-frequency ablation of large, nonresectable hepatic tumors. Am Surg. (2004) 70:1035-8.

19. Mulier S, Ni Y, Jamart J, Ruers T, Marchal G, Michel L. Local recurrence after hepatic radiofrequency coagulation: multivariate meta-analysis and review of contributing factors. Ann Surg. (2005) 242:158-71. doi: 10.1097/01.sla. 0000171032.99149.fe

20. Rajesh S, Mukund A, Arora A, Jain D, Sarin SK. Contrast-enhanced US-guided radiofrequency ablation of hepatocellular carcinoma. J Vasc Interv Radiol. (2013) 24:1235-40.

21. Solbiati L, Ierace T, Tonolini M, Cova L. Guidance and monitoring of radiofrequency liver tumor ablation with contrast-enhanced ultrasound. Eur J Radiol. (2004) 51(Suppl.):S19-23. doi: 10.1016/j.ejrad.2004. 03.035

22. Iguchi T, Hiraki T, Gobara H, Fujiwara H, Matsui Y, Soh J, et al. Percutaneous radiofrequency ablation of lung cancer presenting as ground-glass opacity. Cardiovasc Intervent Radiol. (2015) 38:409-15.

23. Sommer CM, Lemm G, Hohenstein E, Bellemann N, Stampfl U, Goezen AS, et al. CT-guided bipolar and multipolar radiofrequency ablation (RF ablation) of renal cell carcinoma: specific technical aspects and clinical results. Cardiovasc Intervent Radiol. (2013) 36:731-7. doi: 10.1007/s00270-0120468-z 
24. Takaki H, Yamakado K, Nakatsuka A, Yamada T, Shiraki K, Takei Y, et al. Frequency of and risk factors for complications after liver radiofrequency ablation under CT fluoroscopic guidance in 1500 sessions: single-center experience. AJR Am J Roentgenol. (2013) 200:658-64. doi: 10.2214/AJR.12. 8691

25. Clasen S, Boss A, Schmidt D, Schraml C, Fritz J, Schick F, et al. MR-guided radiofrequency ablation in a $0.2-\mathrm{T}$ open MR system: technical success and technique effectiveness in 100 liver tumors. J Magn Reson Imaging. (2007) 26:1043-52. doi: 10.1002/jmri. 21120

26. Fischbach F, Lohfink K, Gaffke G, Wybranski C, Mohnike K, Wonneberger $\mathrm{U}$, et al. Magnetic resonance-guided freehand radiofrequency ablation of malignant liver lesions: a new simplified and time-efficient approach using an interactive open magnetic resonance scan platform and hepatocytespecific contrast agent. Invest Radiol. (2013) 48:422-8. doi: 10.1097/RLI. 0b013e3182803dae

27. Clasen S, Rempp H, Hoffmann R, Graf H, Pereira PL, Claussen CD. Image-guided radiofrequency ablation of hepatocellular carcinoma (HCC): is MR guidance more effective than CT guidance? Eur J Radiol. (2014) 83:111-6.

28. Nuzzo S, Peyrin F, Cloetens P, Baruchel J, Boivin G. Quantification of the degree of mineralization of bone in three dimensions using synchrotron radiation microtomography. Med Phys. (2002) 29:2672-81. doi: 10.1118/1. 1513161

29. Tang R, Huang W, Yan F, Lu Y, Chai WM, Yang GY, et al. In-line phase contrast imaging of hepatic portal vein embolization with radiolucent embolic agents in mice: a preliminary study. PLoS One. (2013) 8:e80919. doi: 10.1371/journal. pone.0080919

30. Lewis RA. Medical phase contrast $x$-ray imaging: current status and future prospects. Phys Med Biol. (2004) 49:3573-83. doi: 10.1088/0031-9155/49/16/ 005

31. Spanne P, Raven C, Snigireva I, Snigirev A. In-line holography and phasecontrast microtomography with high energy x-rays. Phys Med Biol. (1999) 44:741-9. doi: 10.1088/0031-9155/44/3/016

32. Olubamiji AD, Izadifar Z, Chen DX. Synchrotron imaging techniques for bone and cartilage tissue engineering: potential, current trends, and future directions. Tissue Eng Part B Rev. (2014) 20:503-22. doi: 10.1089/ten.teb.2013. 0493

33. Tang R, Li WX, Huang W, Yan F, Chai WM, Yang GY, et al. CO(2)-based in-line phase contrast imaging of small intestine in mice. Sci Rep. (2013) 3:2313.

34. Pisano ED, Johnston RE, Chapman D, Geradts J, Iacocca MV, Livasy CA, et al. Human breast cancer specimens: diffraction-enhanced imaging with histologic correlation-improved conspicuity of lesion detail compared with digital radiography. Radiology. (2000) 214:895-901. doi: 10.1148/radiology. 214.3.r00mr26895

35. Nouso K, Shiraga K, Uematsu S, Okamoto R, Harada R, Takayama S, et al. Prediction of the ablated area by the spread of microbubbles during radiofrequency ablation of hepatocellular carcinoma. Liver Int. (2005) 25:96772.

36. Zhou Z, Wu S, Wang CY, Ma HY, Lin CC, Tsui PH. Monitoring radiofrequency ablation using real-time ultrasound Nakagami imaging combined with frequency and temporal compounding techniques. PLoS One. (2015) 10:e0118030. doi: 10.1371/journal.pone.0118030

37. Tatli S, Tapan U, Morrison PR, Silverman SG. Radiofrequency ablation: technique and clinical applications. Diagn Interv Radiol. (2012) 18:508-16. doi: 10.4261/1305-3825.DIR.5168-11.1

38. Singh S, Repaka R. Numerical study to establish relationship between coagulation volume and target tip temperature during temperature-controlled radiofrequency ablation. Electromagn Biol Med. (2018) 37:13-22. doi: 10.1080/ 15368378.2017.1422262

39. Chiou SY, Liu JB, Needleman L. Current status of sonographically guided radiofrequency ablation techniques. J Ultrasound Med. (2007) 26:487-99. doi: 10.7863/jum.2007.26.4.487

40. McGhana JP, Dodd GD III. Radiofrequency ablation of the liver: current status. AJR Am J Roentgenol. (2001) 176:3-16. doi: 10.2214/ajr.176.1.1760003

41. Castelli E, Tonutti M, Arfelli F, Longo R, Quaia E, Rigon L, et al. Mammography with synchrotron radiation: first clinical experience with phase-detection technique. Radiology. (2011) 259:684-94.

42. Longo R, Tonutti M, Rigon L, Arfelli F, Dreossi D, Quai E, et al. Clinical study in phase- contrast mammography: image-quality analysis. Philos Trans A Math Phys Eng Sci. (2014) 372:20130025. doi: 10.1098/rsta.2013.0025

43. Labriet H, Nemoz C, Renier M, Berkvens P, Brochard T, Cassagne R, et al. Significant dose reduction using synchrotron radiation computed tomography: first clinical case and application to high resolution CT exams. Sci Rep. (2018) 8:12491.

Conflict of Interest: The authors declare that the research was conducted in the absence of any commercial or financial relationships that could be construed as a potential conflict of interest.

Copyright (c) 2020 Huang, Lu, Tang, Wu, Wang, Ding, Wang and Chen. This is an open-access article distributed under the terms of the Creative Commons Attribution License (CC BY). The use, distribution or reproduction in other forums is permitted, provided the original author(s) and the copyright owner(s) are credited and that the original publication in this journal is cited, in accordance with accepted academic practice. No use, distribution or reproduction is permitted which does not comply with these terms. 